\title{
High Performance SiC MOSFETs for Fault Tolerant Applications
}

\author{
C. Onambele ${ }^{1,2}$, A. Mpanda ${ }^{2}$, F. Giacchetti ${ }^{1}$ and M. Elsied ${ }^{2}$ \\ ${ }^{1}$ Modeling, Information \& Systems Lab (MIS) \\ University of Picardie Jules Verne (UPJV) \\ 14, quai de la Somme, 80082 Amiens, France \\ E-mail: onambele_c@esiee-amiens.fr \\ ${ }^{2}$ Graduate School of Electronic and Electrical Engineering (ESIEE-Amiens) \\ 14, quai de la Somme, 80082 Amiens, France \\ Phone number: +0033 322662 067, e-mail: mpanda@esiee-amiens.fr
}

\begin{abstract}
Harsh environment applications are characterized by exceptional constraints regarding temperature, volume, faulttolerance, efficiency, etc. As the introduction of power electronics in such systems is constantly growing, research activities are essential to get more knowledge on the capabilities of available technologies for such applications: aerospace and renewable energies. This paper evaluates the performance of a Silicon Carbide (SiC) MOSFET transistor for a multiphase power converter for fault-tolerant applications. Two methods are carried out in this study: first, the model provided by the manufacturer is used in simulation for a fault-tolerant electric drive application, then in the same operating conditions, the power module is characterized and its performance evaluated. Both methods lead to high system efficiency around $97-98 \%$ for a $1200 \mathrm{~V}-400 \mathrm{~A} \mathrm{SiC}$ MOSFET transistor module integrated in a $120 \mathrm{~kW}-100 \mathrm{~A}$ 6-phase modular inverter.
\end{abstract}

\section{Key words}

High efficiency, fault-tolerant applications, modular inverter, SiC power MOSFET module, switching characterization.

\section{Introduction}

In some critical applications, lightness, compactness, faulttolerance [1] and high efficiency are all expected from the same high frequency power electronic system. Thus, Silicon Carbide (SiC) power MOSFET modules are serious candidates. For switching frequencies higher than $12 \mathrm{kHz}$, they provide lower power losses than Si devices [2]-[5], increasing the efficiency of $\mathrm{SiC}$ MOSFETs based converters as a result. Low power losses to dissipate favor the reduction of volume and weight of the heat sink. But to achieve the lightest and most efficient system, some parameters can become obstacles for designers: load current, temperature, incomplete datasheet for new devices, etc. Characterization of power modules helps to get specific data from measurements, which are used for electrical performance analysis.

Many studies have successfully carried out the characterization of MOSFET devices [3], [4], [6], [7], although some were limited in current [3], [6], [7]. The studies based the performance analysis on the electrical behavior and the functioning under high temperature. In this paper, conditions or requirements that can be severe for power electronics applications are explained. Then modelbased performance analysis is presented, preceding the characterization of a Dual-SiC power MOSFET module for temperatures varying from $25^{\circ} \mathrm{C}$ to $150^{\circ} \mathrm{C}$ and the measurements-based performance study of an $\mathrm{H}$-bridge inverter. The module tested is the CREE® HT-3201 [8]. The paper evaluates the dynamic performance and the efficiency of a high power multiphase converter $(120 \mathrm{~kW}$ $100 \mathrm{~A}-25 \mathrm{kHz}$ ) based on Silicon Carbide (SiC) technology for fault-tolerant applications.

\section{A. Harsh Intrinsic conditions}

These are probably the first constraints that designers consider as they are directly dependent on the components of the power system. 
High operating voltage and/or current (100A or more) lead to important challenges from the design stage to the prototype manufacturing. As an example, high current MOSFETs are introduced progressively in applications for more electrical aircrafts because their use implies other precautions on power sources, measurement devices, bus bars or power cables, etc.

Efficiency of the system is also a major goal to achieve for some applications. High efficiency (95\% or more) requirements lead to the need of choosing the best technologies which will help to keep high performance despite other constraints.

For applications in need of weight savings such as aerospace, the lighter the system is, the closer the designer can achieve weight objectives. In power electronics applications, the main weight drivers are certainly passive parts such as filters or cooling systems. But when the number of active devices increase, which is the case with fault-tolerant power electronics systems, the individual weight of components becomes a parameter possible help in system weight savings.

\section{B. Environmental conditions}

Ambient temperature, altitude and vibrations are conditions that need to be also considered when designing a power electronics system as they can affect the overall performance of the system. Most electronic devices are manufactured for specific temperature range. For high temperatures, specific devices are chosen, such as the CREE® HT-3201 [8] which is able to maintain their performance. Also, elevated ambient temperatures reduce the chances to achieve an efficient air cooling system. Knowing that maximum junction temperatures of power electronics transistors is around $150^{\circ} \mathrm{C}$, the higher the ambient temperature, the faster the devices will reach absolute maximum temperature values.

When air cooled systems are used based on fans, altitude modifies the fan curves and as a result, the cooling performance. Vibrations are also critical mainly from the mechanical point of view: the sensitivity of the system to vibrations needs to be acceptable. Besides, other climatic conditions can affect the system performance and reliability as described in [9], [10].

\section{System description}

The schematic diagram of the system under consideration is depicted in Fig. 1. This configuration is introduced in this paper for aerospace application. The HVDC bus $(540 \mathrm{~V})$ is interfaced to a hexaphase machine by using multiphase converter and filter. The multiphase power converter is used for power flow control to fulfil power requirements of the machine $(120 \mathrm{~kW})$. In this application, the power converter is composed of six H-bridge inverters based on $\mathrm{SiC}$ MOSFETs. These semiconductors devices can achieve high performance and reliable power conversion as they offer ultra-low losses, and the ability to function at high operating temperatures. The modular topology of the converter allows evaluating its efficiency focusing on the behavior of one phase, assuming the power is equally shared among the phases.

\section{Model-based Performance Evaluation of a $120 \mathrm{~kW}-100 \mathrm{~A}$ 6-phase modular inverter in an H-bridge topology}

The availability of the SiC MOSFET HT-3201 model on LTSpice $\AA$, there is the possibility to assess its performance in a specified application. The model represents a halfbridge module composed of detailed models of $\mathrm{SiC}$ switches, schottky diodes and parasitic inductances of the package included by the manufacturer: from the inner drain, source and gate of each switch to the outer connections. Parasitic inductances between two switches are also included. These parasitic elements also depend on the implementation and may impact the measurements later. Hence, a full-bridge inverter is modeled on LTSpice $\AA$ environment, as shown in Fig. 2. Considering that all the switches have the same gate resistance, simulations show that the higher the gate resistance, the lower the efficiency. The gate resistance value chosen is $2.2 \Omega$. The module was simulated beforehand with the double pulse test scheme [5] shown in Fig. 5. Results of this first simulation show some good performance in the switching behavior (Fig. 3). In fact, the overvoltage in the turn-off operation is very low (about $5 \%$ ) and the total switching losses computed is around $5 \mathrm{~mJ}$ (turn-on and turn-off). But the current overshoot at turn-on is quite high (more than the double of the 100A objective), but is still below the $400 \mathrm{~A}$ rating of the device.

In order to compute the efficiency of the inverter of Fig. 2, some spice directives have been added allowing the following calculations in steady-state regime: average input power, average output power, resulting losses and resulting efficiency. The latter is expressed as:

$$
\text { Converter }_{\text {Efficiency }}=\frac{\text { Average output power }}{\text { Average input power }}
$$

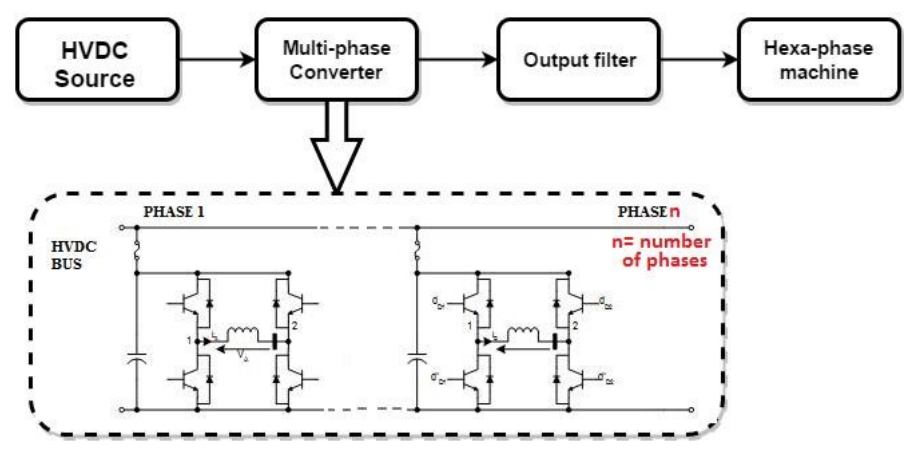

Fig. 1. System description showing only two phases of the power converter 
In Fig. 4 are shown the results of the simulation, knowing that the following inputs have been imposed, extracted from a Simulink ${ }^{\circledR}$ control model: Gate drive voltages (d1_high, d1_low, d2_high and d2_low), BEMF voltage source and load or phase current. Table I contains the post-processing results which are to be confirmed by following tests and measurements.

\section{SiC MOSFET Switching Characterization}

This paragraph describes the activities undertaken in order to measure the turn-on and turn-off switching energies of one MOSFET of the HT-3201 power module, which scheme is given in Fig. 5 [8].Each transistor corresponds to a 4leaded component, the kelvin source connection contributing to better system performance, absent in 3leaded components [11]. The module is tested along with its gate driver ITGD2-3001 from CREE®.

\section{Gate driver ITGD2-3001 functionality test}

The half-bridge gate driver is configured to supply the lower MOSFET of the module. It includes a gate resistance of $5 \Omega$ for each switch driver. The goal of the test is to keep the upper transistor off $(\mathrm{d} 1$ _high $=-5 \mathrm{~V})$ and to provide appropriate command signals to the lower transistor $(d 1$ low $=-5 /+20 \mathrm{~V})$. Here, the gate driver inputs need a pair of signals from a differential source. But because of the unavailability of such source, the positive line input is connected to the logic rail and the negative line input to the midpoint of the logic rail. The test is made at room temperature using a DC current source, a scope and a frequency generator, to provide the command signal (logic rail). Fig. 6 shows the gate driver output signals Vgs1 (-5V) and Vgs2 $(-5 /+20 \mathrm{~V})$, resulting from a command signal $\mathrm{Vcmd}$, set to $0 /+5 \mathrm{~V}$ with $20 \mathrm{kHz}$ frequency. This signal is connected to the positive line of the differential inputs and the negative line is connected to $2.5 \mathrm{~V}$. The minimum high level value of the PWM signal needed to achieve $-5 /+20 \mathrm{~V}$ at Vgs2 is obtained experimentally: $+2.7 \mathrm{~V}$.

\section{B. Test of the half-bridge HT-3201 power MOSFET module}

\section{1) Test setup and conditions}

The power module is assembled with the gate driver and placed on a hotplate. The latter is used for testing the device for temperatures varying from 25 to $150^{\circ} \mathrm{C}$. The well-known double-pulse test method [5], which setup scheme is given in Fig. 5, is used to measure the switching characteristics of the lower MOSFET, knowing that the upper MOSFET will behave the same under similar conditions. The method consists in supplying the gate driver with a voltage of two pulses of different lengths: the first pulse is the shortest and is used to measure the turn-off losses at the falling stage of the pulse and the second one which is generally five to ten times longer, is used to measure the turn-on losses at the rising stage. The actual length depends on the current that is to be achieved at the end of the first pulse. It is found through testing.

The layout of the setup is given in Fig. 7. It is composed by: - an aluminum hot plate which is used to heat the power module thanks to the hot oil flowing inside; - a DC bus capacitor (black part on the left side of the image) of $120 \mu \mathrm{F}$ placed on the top of the hot plate via a wooden plate to create an air gap between the hot plate and the capacitor, avoiding to overheat the capacitor; - the $\mathrm{SiC}$ power module placed on the hot plate via thermal grease and fixation screws, and close to the capacitor with copper bus bars for connections; -the gate driver fixed on top of the module and characterized by a $5 \Omega$ gate resistor per switch; and a custom input/output board for the gate driver. As it can be seen, the assembly achieved is very compact to limit additional parasitic inductances.

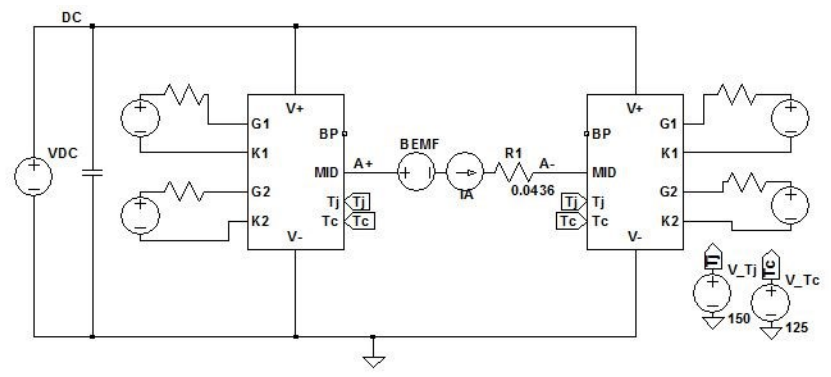

Fig. 2. Full-bridge scheme on LTSpice ${ }^{\circledR}$ with one-phase equivalent circuit model of the machine
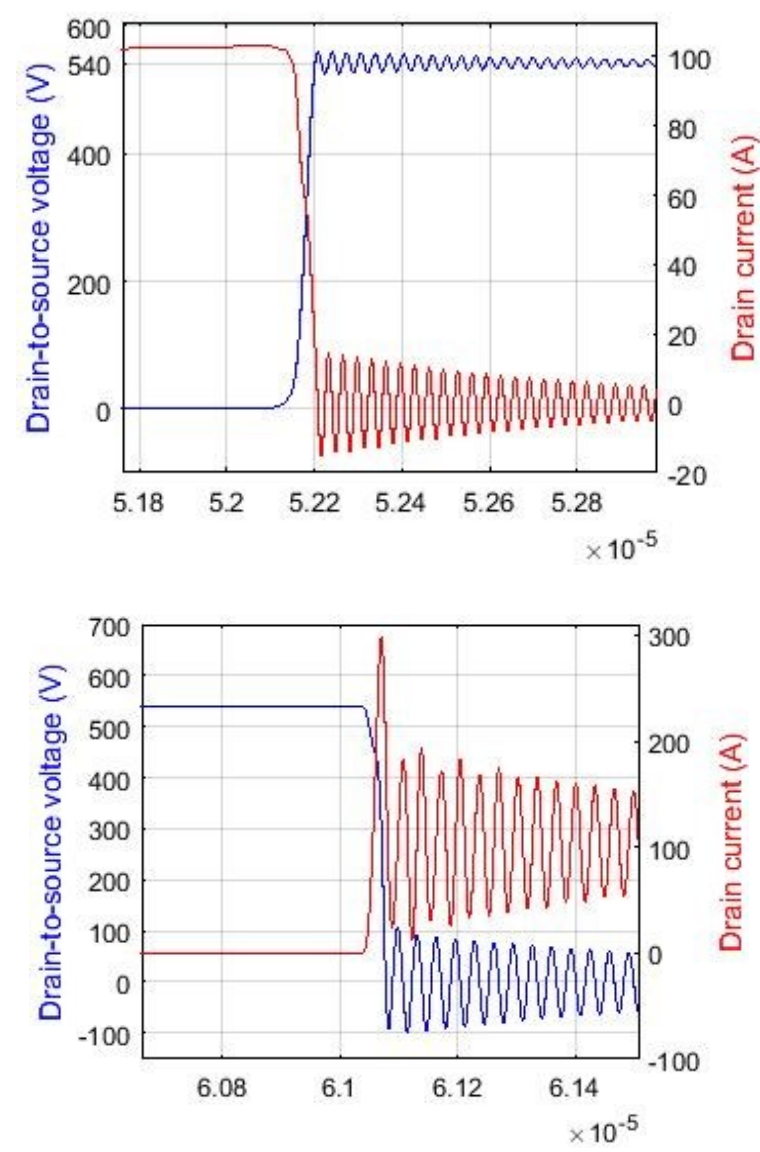

Fig. 3. Double-pulse simulation - Turn-Off (Top), Turn-On (Bottom): Voltage (blue) and Current (red) 
Table II summarizes the different switching tests carried out for different case temperatures at a specific operating condition: 540VDC $-100 \mathrm{~A}$. The maximum admissible current of the module is $400 \mathrm{~A}$ for $25^{\circ} \mathrm{C}$ case temperature and $170 \mathrm{~A}$ for $175^{\circ} \mathrm{C}$. Therefore, a current of $100 \mathrm{~A}$ was chosen to ensure a safety margin at a temperature of $150^{\circ} \mathrm{C}$.

\section{2) Double pulse test results and comparison with simulation}

Switching waveforms consist of turn-on and turn-off characteristics: drain current and drain-source voltage. Using some features of the Tektronix ${ }^{\circledR}$ oscilloscope, it is possible to obtain switching power waveforms and to compute the switching energies. Fig. 8 shows an example of switching tests results. The tests give similar results compared to the simulation performed above (Fig. 3). The different energy losses obtained for the different tests are reported in Table III.

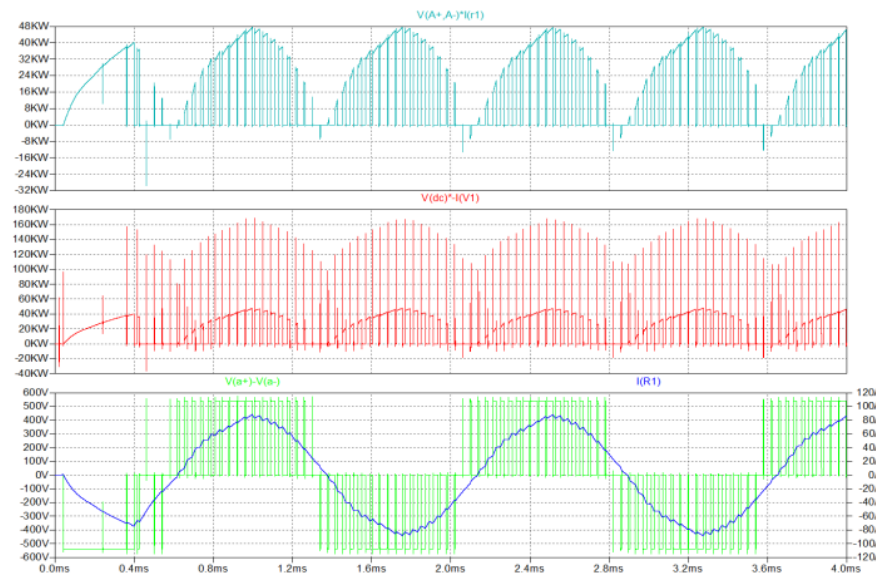

Fig. 4. Full-bridge simulation results on LTSpice - From top to bottom: Output power, input power, load current(blue) output voltage (green)

Table I. - Post-processing results using Spice directives in steadystate regime

\begin{tabular}{|c|c|c|c|c|}
\hline $\begin{array}{c}\text { Switching } \\
\text { frequency } \\
{[\mathbf{k H z}]}\end{array}$ & $\begin{array}{c}\text { Average } \\
\text { Input } \\
\text { power } \\
{[\mathbf{k W}]}\end{array}$ & $\begin{array}{c}\text { Average } \\
\text { Output } \\
\text { power } \\
{[\mathbf{k W}]}\end{array}$ & $\begin{array}{c}\text { Average } \\
\text { Power } \\
\text { losses } \\
{[\mathbf{W}]}\end{array}$ & $\begin{array}{c}\text { Efficiency } \\
{[\%]}\end{array}$ \\
\hline $\mathbf{2 5 \mathbf { k H z }}$ & 17.63 & 17.28 & 355 & 97.9 \\
\hline $\mathbf{1 2 . 5 \mathbf { k H z }}$ & 16.1 & 15.92 & 184 & 98.9 \\
\hline
\end{tabular}

Table II. - Conditions of the switching tests of the half-bridge SiC module

\begin{tabular}{|c|c|}
\hline $\begin{array}{c}\text { Number } \\
\text { of tests }\end{array}$ & Details of the test conditions \\
\hline & Test $1: 25^{\circ} \mathrm{C}-540 \mathrm{VDC}-100 \mathrm{~A}$ \\
& Test $2: 100^{\circ} \mathrm{C}-540 \mathrm{VDC}-100 \mathrm{~A}$ \\
& Test $3: 125^{\circ} \mathrm{C}-540 \mathrm{VDC}-100 \mathrm{~A}$ \\
& Test $4: 150^{\circ} \mathrm{C}-540 \mathrm{VDC}-100 \mathrm{~A}$ \\
\hline
\end{tabular}

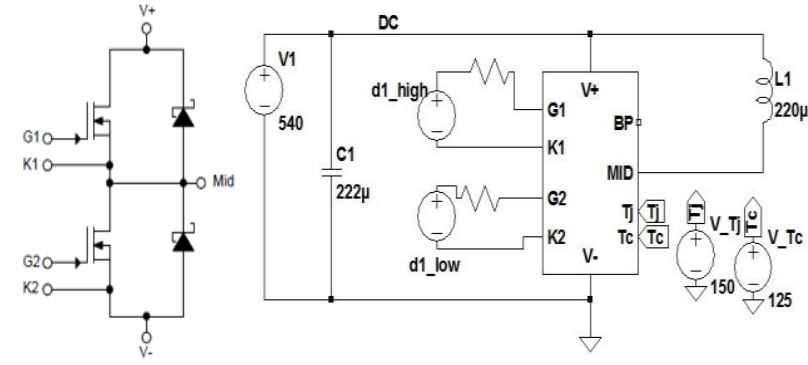

Fig. 5. SiC module HT-3201 (left) - Double-pulse test setup scheme (right)

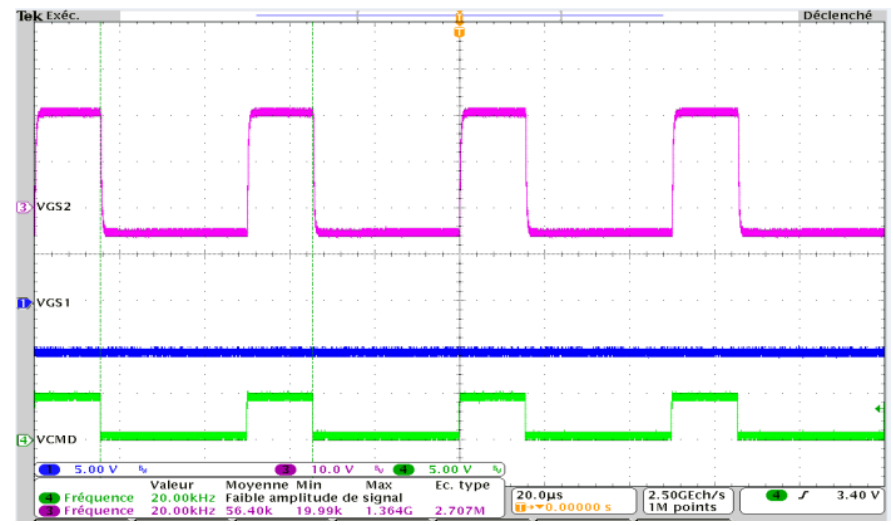

Fig. 6. Gate driver output signals - From top: Vgs2; Vgs1; Vcmd

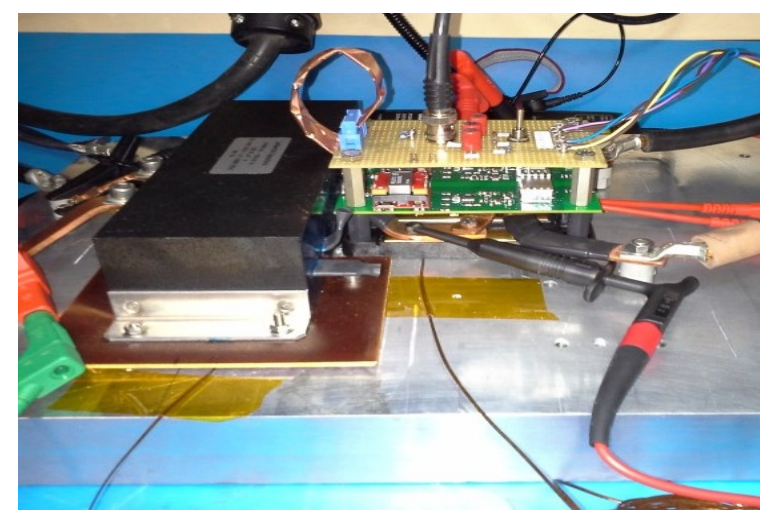

Fig. 7. Test setup for the characterization of the CREE® HT-3201 module

Table III. - Energy losses for different tests at 540VDC and 100A maximum current

\begin{tabular}{|c|c|c|c|}
\hline $\begin{array}{c}\text { Details of the test } \\
\text { conditions }\end{array}$ & $\begin{array}{c}\text { Turn On } \\
\text { Energy } \\
\text { losses (mJ) }\end{array}$ & $\begin{array}{c}\text { Turn Off } \\
\text { Energy losses } \\
\text { (mJ) }\end{array}$ & $\begin{array}{c}\text { Total energy } \\
\text { losses (mJ) }\end{array}$ \\
\hline Test $\mathbf{1 :} \mathbf{2 5}^{\circ} \mathbf{C}$ & 4.3 & 1.9 & 6.2 \\
\hline Test $2: \mathbf{1 0 0}^{\circ} \mathbf{C}$ & 5.3 & 2.6 & 7.9 \\
\hline Test $3: \mathbf{1 2 5}^{\circ} \mathbf{C}$ & 5.6 & 3.7 & 9.3 \\
\hline Test $4: \mathbf{1 5 0}^{\circ} \mathbf{C}$ & 5.8 & 3.1 & 8.9 \\
\hline
\end{tabular}



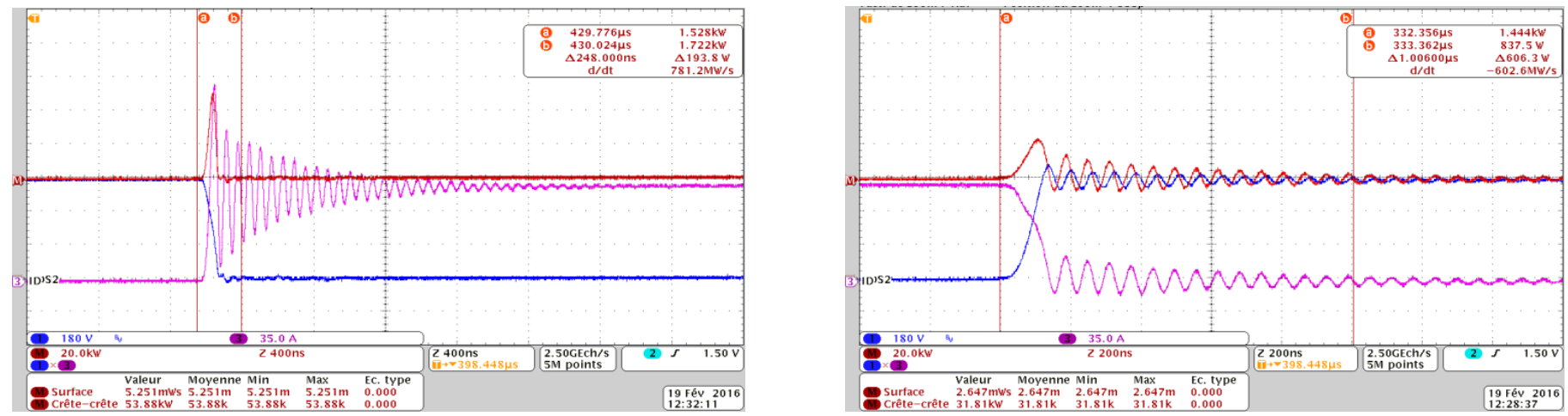

Fig. 8. Test 3- Turn On (left) - Turn Off (right): Drain-Source voltage (blue); Drain current (purple); Power (red)

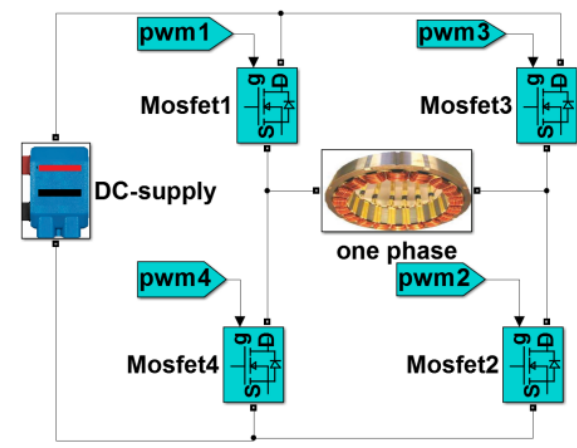

Fig. 9. Independent phase powered in H-bridge configuration simulated in MATLAB/Simulink ${ }^{\circledR}$

Results show that the higher the case temperature is, the higher the energy losses will be. For example, an increase of the temperature from $25^{\circ} \mathrm{C}$ to $100^{\circ} \mathrm{C}$ (tests 1 and 2) at the same voltage and current conditions lead to an increase in the total switching losses of about $27 \%$. At temperatures very close to the maximum admissible for the module (tests 3 and 4), the behavior is slightly different. What can be underlined is that a change in temperature of $25^{\circ} \mathrm{C}$ in this region does not severely affect the total switching losses.

\section{Measurements-based Performance evaluation of a $120 \mathrm{~kW}-100 \mathrm{~A}-25 \mathrm{kHz} 6-$ phase modular inverter in an $\mathrm{H}$-bridge topology}

To evaluate the performance of the $\mathrm{SiC}$ module, a full-bridge inverter is modeled in Simulink ${ }^{\circledR}$ environment, as shown in Fig. 9.

Because the machine which model is used in paragraph II is under construction and thus unavailable for tests at system level, double pulse tests results are used to compute efficiency of the converter with a one-phase model of the machine on MATLAB/Simulink platform.

The losses calculations consider only conduction and switching losses of the modules (MOSFETs and diodes), neglecting other losses such as driver losses: the total energy losses are taken to be $10 \mathrm{~mJ}$, corresponding to the measurement results of test 3 , which is supposed to be the worst case with a current of 100A. Simulation assumes a unipolar sinusoidal PWM scheme and following equations are used in MATLAB ${ }^{\circledR}$ to compute the power losses:

$$
\begin{aligned}
& P_{M}=P_{C M}+P_{s w M} \\
& P_{M}=R_{D S o n} I_{D r m s}^{2}+\left(E_{\text {onM }}+E_{\text {off } M}\right) f_{s w} \\
& P_{D}=P_{C D}+P_{\text {swD }} \\
& P_{D}=u_{D 0} I_{F a v}+R_{D} I_{F r m s}^{2}+E_{\text {onD }} f_{\text {sw }}
\end{aligned}
$$

Where $\mathrm{P}_{\mathrm{CM}}$ and $\mathrm{P}_{\mathrm{SWM}}$ are MOSFET conducting and switching losses respectively, $\mathrm{P}_{\mathrm{CD}}$ and $\mathrm{P}_{\mathrm{SWD}}$ are body diode conduction and switching losses, and $\mathrm{PM}$ and $\mathrm{PD}$ are MOSFET and Diode total losses. Parameters $R_{D S o n}$ and $R_{D}$ are MOSFET On-state resistance and diode forward resistance. Parameter $\mathrm{u}_{\mathrm{D} 0}$ is the forward voltage of the diode during conduction, $\mathrm{I}_{\mathrm{Drms}}$ is the MOSFET root-mean-square value of the drain current, $\mathrm{I}_{\mathrm{Frms}}$ is the forward current of the diode and $\mathrm{I}_{\mathrm{Fav}}$ is the average forward current of the diode. $\left(E_{\text {onM }}+E_{\text {off }}\right)$ is equivalent to the total energy losses measured and considered to be $10 \mathrm{~mJ}$. $\mathrm{E}_{\mathrm{onD}}$ corresponds to body diodes losses which are negligible, compared to MOSFETs losses. To compute the efficiency of the converter, the following equations are used:

$$
\begin{aligned}
& P_{\text {in }_{\text {converter }}}=V_{D C} I_{\text {supply }_{\text {rms }}} \\
& P_{o_{\text {converter }}}=P_{\text {in }_{\text {converter }}}-P_{\text {losses }} \\
& \text { Efficiency }=P_{o_{\text {converter }}} / P_{\text {in }} \text { converter }
\end{aligned}
$$

With $\mathrm{P}_{\mathrm{in}_{\text {converter }}}$ and $\mathrm{P}_{\mathrm{o}_{\text {converter }}}$ representing the converter's input and output power respectively, $\mathrm{V}_{\mathrm{DC}}$ the DC supply voltage and $\mathrm{I}_{\text {supply }}{ }_{\mathrm{rms}}$, the root-mean-square value of the supply current.

Fig. 10 shows the efficiency curve in function of the switching frequency. The efficiency achieved for the converter is around $97 \%$, at a switching frequency of 25 $\mathrm{kHz}$, and $98 \%$ at a switching frequency of $12.5 \mathrm{kHz}$. 


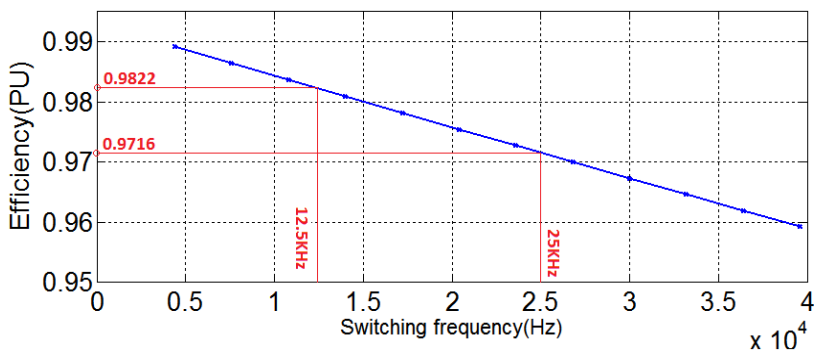

Fig. 10. Efficiency in function of switching frequency

Table IV. - Comparison between model-based and measurementsbased efficiency computations

\begin{tabular}{|c|c|c|}
\hline $\begin{array}{c}\text { Switching } \\
\text { frequency } \\
{[\mathbf{k H z}]}\end{array}$ & $\begin{array}{c}\text { Model-based } \\
\text { Efficiency } \\
{[\%]}\end{array}$ & $\begin{array}{c}\text { Measurements- } \\
\text { based } \\
\text { Efficiency [\%] }\end{array}$ \\
\hline $\mathbf{2 5 \mathrm { kHz }}$ & 97.9 & 97.1 \\
\hline $\mathbf{1 2 . 5 \mathrm { kHz }}$ & 98.9 & 98.2 \\
\hline
\end{tabular}

Using (6), (7) and (8), efficiencies are computed and results are given in Table IV. It can be remarked that the efficiencies from the two methods are close to each other. The achieved results show that $\mathrm{SiC}$ MOSFETs can be used in applications where high efficiency is required. Evaluations of the efficiency levels as reported in this paper help to determine the maximum switching frequency needed for the minimum system efficiency.

\section{Conclusion}

This paper reports the performance evaluation of a high performance Silicon Carbide (SiC) MOSFET transistor for a multiphase converter for fault-tolerant applications such as in aerospace. System efficiency has been computed using LTSpice model provided by the vendor and measurements with the actual power module to validate the model behavior and its results. The power module and its gate driver were used for the tests activities. Based on the double-pulse test method, the characterization of the switches was carried out for an operating condition of a multiphase inverter with different temperatures for the switches.

The system considered is a $120 \mathrm{~kW}-100 \mathrm{~A}-25 \mathrm{kHz}$ 6-phase modular inverter in an $\mathrm{H}$-bridge topology. The converter efficiency achieved is around $97-98 \%$ for a switching frequency around $12.5-25 \mathrm{kHz}$, for a current of $100 \mathrm{~A}$ peak value. The higher the switching frequency gets, the higher switching losses will be. In other words, the module is a valuable candidate for fault-tolerant applications aiming for high efficiency at similar power and switching frequency levels.

\section{Acknowledgement}

This work was done in the frame of JTI Clean Sky Systems for Green Operations WP2.3.4.2 ETRD "Electrical Tail Rotor Drive" and is associated with SoW S632 AH Hybrid Propulsion_2015. Besides, the authors are grateful to CREE ${ }^{\circledR}$ which provided the LTSpice model of the module and advice for proper use of the devices.

\section{References}

[1] M. Villani, M. Tursini, G. Fabri, and L. Castellini, 'High Reliability Permanent Magnet Brushless Motor Drive for Aircraft Application', IEEE Trans. Ind. Electron., vol. 59, no. 5, pp. 2073 2081, May 2012.

[2] R. Yapa, A. J. Forsyth, and R. Todd, 'Analysis of SiC technology in two-level and three-level converters for aerospace applications', in Power Electronics, Machines and Drives (PEMD 2014), 7th IET International Conference on, 2014, pp. 1-6.

[3] Z. Chen, D. Boroyevich, R. Burgos, and F. Wang, 'Characterization and modeling of $1.2 \mathrm{kv}, 20 \mathrm{~A}$ SiC MOSFETs', in Energy Conversion Congress and Exposition, 2009. ECCE 2009. IEEE, 2009, pp. 1480-1487.

[4] J. Fabre, P. Ladoux, and M. Piton, 'Characterization and Implementation of Dual-SiC MOSFET Modules for Future Use in Traction Converters', IEEE Trans. Power Electron., vol. 30, no. 8 , pp. 4079-4090, Aug. 2015.

[5] J. Biela, M. Schweizer, S. Waffler, and J. W. Kolar, 'SiC versus Si\&\#x2014;Evaluation of Potentials for Performance Improvement of Inverter and DC\&\#x2013;DC Converter Systems by SiC Power Semiconductors', IEEE Trans. Ind. Electron., vol. 58, no. 7, pp. 2872-2882, Jul. 2011.

[6] F. Kato, R. Simanjorang, F. Lang, H. Nakagawa, H. Yamaguchi, and H. Sato, ' $250{ }^{\circ} \mathrm{C}$-Operated sandwich-structured all-SiC power module', Jpn. J. Appl. Phys., vol. 54, no. 4S, p. 04DP06, Apr. 2015.

[7] G. Wang et al., 'Static and dynamic performance characterization and comparison of $15 \mathrm{kV} \mathrm{SiC} \mathrm{MOSFET} \mathrm{and} 15 \mathrm{kV} \mathrm{SiC} \mathrm{n-IGBTs',}$ in 2015 IEEE 27th International Symposium on Power Semiconductor Devices IC's (ISPSD), 2015, pp. 229-232.

[8] '[Online]. Available: http://www.apei.net/products/ht-3000.aspx'. .

[9] X. Xinjian and Dingfei-Ge, 'Research on reliability evaluation of electronic products under environmental conditions', in Fifth World Congress on Intelligent Control and Automation, 2004. WCICA 2004, 2004, vol. 4, p. 3146-3149 Vol.4.

[10] R. Ciprian and B. Lehman, 'Modeling effects of relative humidity, moisture, and extreme environmental conditions on power electronic performance', in IEEE Energy Conversion Congress and Exposition, 2009. ECCE 2009, 2009, pp. 1052-1059.

[11] V. Crisafulli, 'A new package with kelvin source connection for increasing power density in power electronics design', in 2015 17th European Conference on Power Electronics and Applications (EPE'15 ECCE-Europe), 2015, pp. 1-8. 